\title{
A Mathematical Model for Calculating the "Brittleness-Ductility" Drop Coefficient of Sandstone in Mining Zones
}

\author{
Guodong Shi, ${ }^{1,2}$ Baoquan Cheng $\mathbb{D}^{1,2}$ and $\mathrm{An} \mathrm{Li}^{1,2}$ \\ ${ }^{1}$ School of Civil Engineering, Anhui Jianzhu University, Hefei, Anhui 230601, China \\ ${ }^{2}$ National-Local Joint Engineering Laboratory of Structural Health Monitoring and Disaster Prevention Technology, Hefei, \\ Anhui 230601, China \\ Correspondence should be addressed to Baoquan Cheng; curtis_ch@163.com
}

Received 25 April 2020; Accepted 21 May 2020; Published 8 July 2020

Guest Editor: Shaohui Wang

Copyright (c) 2020 Guodong Shi et al. This is an open access article distributed under the Creative Commons Attribution License, which permits unrestricted use, distribution, and reproduction in any medium, provided the original work is properly cited.

Sandstone is different from pure brittle rocks such as marble and granite. Its brittleness weakens and then increases with increasing confining pressure. This paper establishes a calculation model of the "brittleness-ductility" energy drop coefficient that characterizes the whole process of sandstone failure from the perspective of energy. The obtained result was compared with the result of traditional calculation model. The results show that the established model is more consistent with the experimental phenomenon and can describe the whole process of sandstone failure more precisely at a macro level. Moreover, the model is more practical since it avoids the tedious integration calculation process. The model and tests have extended the applicable range and applied rock types of the energy drop coefficient and enriched the knowledge system of elastoplastic mechanics. At the same time, they carry important significance for environmental restoration and geological disaster prevention and control in sedimentary rock mining zones, which can promote the sustainable development of related industries in the mining zones.

\section{Introduction}

China is one of the few countries in the world which use coal as the main energy source. Its coal output has exceeded onethird of the world's total $[1,2]$. Resource destruction, environmental damage, and industrial accidents related to coal production are very prominent $[3,4]$. In particular, during the construction of new mine and waste mine backfilling, frequent mine collapses threaten the safety of workers and their property, seriously damage the ecological environment and groundwater quality, or even trigger more severe geographic hazards [5-7]. The sustainable development of coal resources and related industries is facing challenges. Sandstone is the most common surrounding rock in coal mines in China [8]. Frequent landslides are often closely related to the failure of sandstone. Therefore, a deep understanding of its failure mechanism can ensure the safety of mine construction and exploitation $[9,10]$. In addition, it helps to prevent the negative impact of mining industry on the surroundings and has far-reaching significance for environmental restoration and disaster prevention and control in the mining zones.

In traditional elastic-plastic mechanics theory, the stressstrain curve is usually used to describe the process of material deformation and failure, thus establishing the constitutive model of the material and the corresponding strength theory. For linear elastic materials, this method can be used to reflect mechanical characteristics of the material accurately. However, due to the anisotropy and inhomogeneity of the material, the stress-strain relationship of the rock is distinctively nonlinear $[5,11]$. As a result, for stones it is difficult to establish a reasonable strength criterion based on the stress-strain curve alone. In fact, the loading process is a process of exerting external energy input. Before its stress reaches the peak, the rock absorbs and stores the external energy taking advantage of its own elastoplasticity to maintain a stable state [12-14]. At the peak intensity, the rock is in a critical state of high energy instability [15]. With the continuous input of external energy, the rock finally releases the stored energy and loses its stability, and the 
stress quickly drops to the residual strength $[16,17]$. This means that the rock deformation and failure process is an irreversible process of energy release and dissipation. The ultimate failure of the rock is actually a sudden change in the process of energy dissipation. Therefore, to describe the deformation and failure process of rocks from the perspective of energy can better reflect the physical nature of its failure mechanism.

In recent years, many researchers have studied the failure mechanism of brittle rocks based on energy analysis. Zhao et al. demonstrated in detail that the failure mode and energy dissipation process change with the anisotropy, inhomogeneity, and stress state of rocks and proposed the principle of minimum energy for dynamic failure based on the findings [18]. Yang et al. performed triaxial tests on marble rocks by using servo machines to investigate the deformation and failure process of rock samples and their energy characteristics [19]. Su et al. studied the patterns of plastic deformation, uniaxial compression strength, average modulus, energy dissipation, and failure characteristics of rock samples during triaxial tests [20]. Xie et al. proposed failure criterion for stratified rock based on distortion energy and generalized volume expansion potential energy, which was in good agreement with the results of the double pressure tests. The established rock damage evolution equation was verified through experiments, and related parameter indicators were determined [21]. Zuo et al. analyzed the shortcomings of the stress drop coefficient of brittle rocks and put forward a new characterization parameter of rock failure-the energy drop coefficient [22]. Song et al. analyzed the applicability and limitation of the energy drop coefficient and further considered the proportion of releasable elastic energy in the total energy before peak stage to present an improved energy drop coefficient [23]. Liu et al. presented valency-based topological indices of chemical networks $[24,25]$. By using some real world data, we performed certain comparative testing to investigate the performance of almost all well-known valencybased indices. In light of this, many scholars have rediscovered the changes in the stress-strain state of rocks under external loads from an energy perspective and analyzed the energy transfer and conversion in the process of rock deformation and failure in order to establish the strength theory using energy changes as failure criteria, which is a more realistic description of the failure mechanism of rocks.

However, there are some strong limitations in current researches. First, these energy threshold values reflecting rock strength usually only take into account the energy evolution characteristics of the postpeak stage and thus cannot reflect the entire process of rock deformation and failure [26]. Second, the calculation of the traditional energy drop coefficient of rocks mainly requires a large number of integral calculations, which is cumbersome and inconvenient. Third, previous studies have used magmatic rocks and metamorphic rocks such as marble and granite as research objects more, and few studies have been conducted on sedimentary rocks such as sandstone [27]. To address these research gaps, this paper obtains the whole stress-strain curves of sandstones under different confining pressures based on triaxial tests and proposes a calculation model of "brittleness-ductility" energy drop coefficient applicable to sandstone. Based on established model, the mechanism of sandstone failure is explained and influence of confining pressure on energy release and dissipation during rock deformation and failure is discussed.

The calculation model of "brittleness-ductility" energy drop coefficient proposed in this paper can truly describe the no-linear deformation and failure process of sandstone. The model fully considers the two states before and after the failure of the rock samples and further enriches the physical meaning of the traditional stress-strain curve in describing material failure mechanism, which can provide references for studies on other rocks with similar mechanical characteristics. In addition, the model can efficiently calculate and characterize the mechanical properties of sandstone and provide a reference for the comprehensive development and management of mining zones, which is beneficial to the environmental restoration and geological disaster prevention in these zones. The study can promote the sustainable development of related industries as well.

\section{Energy Drop Coefficient of Rock Based on Triaxial Tests}

The rock triaxial test is essentially a simulation of the mechanical properties of the rock in a three-way compression environment. Compared to conventional test methods, triaxial tests are more intricately advanced tests, which can obtain compressive strength, shear strength, elastic modulus, Poisson's ratio, cohesion, and internal friction angle under different confining pressures (or depths) of rocks. Without changing the ambient temperature, the heat exchange between the test piece and the environment can be ignored. Therefore, the energy conversion of the test piece during the tests is mainly mechanical energy exchange with the test machine.

In the test, the work done by the testing machine for the axial compression of test piece is

$$
W_{z}=\int F_{z} \mathrm{~d} z=\frac{\pi d^{2}}{4} h \int \sigma_{z} \mathrm{~d} \varepsilon_{z}
$$

where $W_{z}$ is the work done by the testing machine for the axial compression, and it is also the total energy input into the test piece. $F_{z}$ is the axial equivalent effect, $d$ the diameter of the test piece, $h$ the height, $\sigma_{z}$ the axial stress, and $\varepsilon_{z}$ the axial strain.

For the triaxial test with constant confining pressure, the work done by the test piece in the circumferential direction on the hydraulic oil is

$$
W_{r}=\int F_{r} \mathrm{~d} r=\frac{\pi d^{2}}{2} h \int \sigma_{r} \mathrm{~d} \varepsilon_{r}
$$

where $F_{r}$ is the circumferential equivalent force, $d$ the diameter of the test piece, $h$ the height, $\sigma_{z}$ the radial stress, and $\varepsilon_{z}$ the radial strain.

From (1) and (2), it can be known that the actual mechanical energy absorbed by the sample $W$ is the difference between $W_{z}$ and $W_{r}$ : 


$$
W=W_{z}-W_{r}
$$

It is difficult to measure $W_{z}$ and $W_{r}$ directly from the tests. In fact, the deformation and failure of the pieces essentially result from the continuous dissipation and rapid release of energy. It means that part of the input mechanical energy is released as elastic energy and the other converted to dissipative energy. Therefore, the actual mechanical energy $W$ absorbed when the test piece reaches the peak pressure can be divided into dissipative energy and releasable elastic energy:

$$
W=W_{p}+W_{e},
$$

where $W_{p}$ is dissipative energy and $W_{e}$ is releasable elastic energy. Figure 1 shows the typical stress-strain curve of rocks. $W_{p}$ corresponds to the area enclosed by the OAB and $W_{e}$ corresponds to the area enclosed by the BAC.

When the axial strain is $\varepsilon$, according to (1)-(4), the energy absorbed by the test piece is $W(\varepsilon)$ and is equal to the work performed by the test machine on the test piece:

$$
W=W_{p} W(\varepsilon)=V\left[\int_{0}^{\varepsilon} \sigma_{z} \mathrm{~d} \varepsilon_{z}-2 \int_{0}^{\mu \varepsilon} \sigma_{r} \mathrm{~d} \varepsilon_{r}\right]+W_{e}
$$

where $V$ is the volume of the test piece; $\sigma_{z}, \varepsilon_{z}, \sigma_{r}$, and $\varepsilon_{r}$ are integral variables; $\varepsilon$ is the axial strain; and $\mu$ is the Poisson's ratio.

When the confining pressure remains unchanged, $W_{e}$, the elastic energy released by the rock, can be measured by the unloading test. If the elastic modulus of the test piece is $\mathrm{E}$,

$$
W_{e}(\varepsilon)=V\left(\frac{1}{2} \sigma_{z} \varepsilon^{e}+\mu \varepsilon^{e} \sigma_{r}\right)
$$

where $\mathrm{E}$ is the elastic modulus of the test piece and $\varepsilon^{e}$ is recoverable elastic strain:

$$
\varepsilon^{e}=\frac{1}{\mathrm{E}}\left(\sigma_{z}-2 \mu \sigma_{r}\right)
$$

From (6) and (7), it can be known that

$$
W_{e}(\varepsilon)=\frac{V}{\mathrm{E}}\left(\sigma_{z}-2 \mu \sigma_{r}\right)\left(\frac{1}{2} \sigma_{z}+\mu \sigma_{r}\right) .
$$

When the stress drops from point $\mathrm{A}$ to point $\mathrm{D}$, the change of releasable elastic energy is

$$
\Delta W_{e}(\varepsilon)=W_{e}\left(\varepsilon_{\mathrm{A}}\right)-W_{e}\left(\varepsilon_{\mathrm{D}}\right)=V\left(\frac{\sigma_{\mathrm{A}}^{2}}{2 \mathrm{E}_{\mathrm{A}}}-\frac{\sigma_{\mathrm{D}}^{2}}{2 \mathrm{E}_{\mathrm{D}}}\right) .
$$

According to (5), when confining pressure is constant, the stress drops from point $A$ to point $D$, and the externally input mechanical energy $\Delta W$ is

$$
\Delta W=V\left[\int_{\varepsilon_{\mathrm{A}}}^{\varepsilon_{\mathrm{D}}} \sigma_{z} \mathrm{~d} \varepsilon_{z}-2 \mu\left(\varepsilon_{\mathrm{D}}-\varepsilon_{\mathrm{A}}\right) \sigma_{r}\right]
$$

The ratio of $\Delta W$ and $\Delta W_{e}$ is used to characterize the energy change during the stress drop when the test piece fails. This ratio $\mathrm{H}$ is defined as the energy drop coefficient of the rocks:

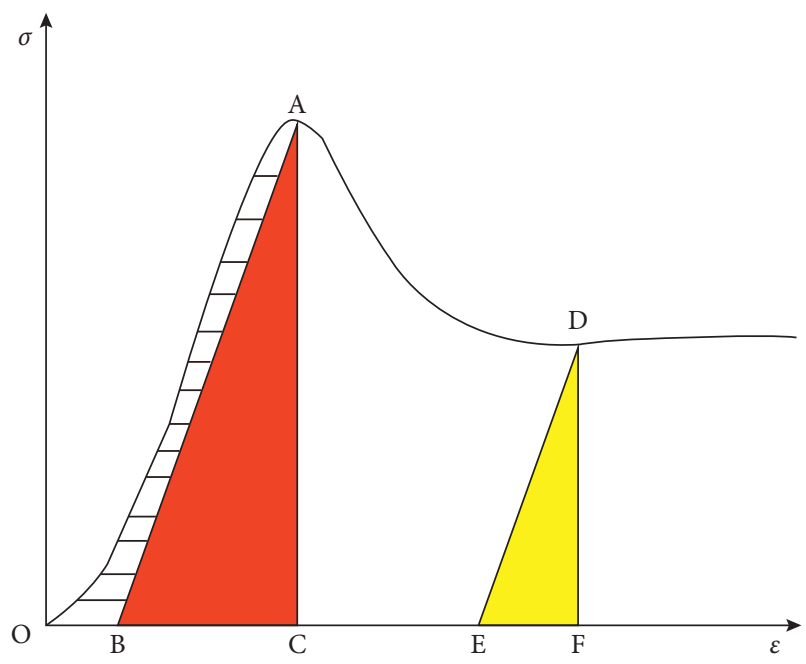

Figure 1: Typical stress-strain curve of rocks.

$$
H=\frac{\Delta W}{\Delta W_{e}}=\frac{\int_{\varepsilon_{\mathrm{A}}}^{\varepsilon_{\mathrm{D}}} \sigma_{z} \mathrm{~d} \varepsilon_{z}-2 \mu\left(\varepsilon_{\mathrm{D}}-\varepsilon_{\mathrm{A}}\right) \sigma_{r}}{\left(\sigma_{\mathrm{A}}^{2} / 2 \mathrm{E}_{\mathrm{A}}\right)-\left(\sigma_{\mathrm{D}}^{2} / 2 \mathrm{E}_{\mathrm{D}}\right)},
$$

where $\sigma_{\mathrm{A}}$ and $\varepsilon_{\mathrm{A}}$ are the peak stress and peak strain, respectively; $\mu$ is the Poisson's ratio; $\sigma_{\mathrm{D}}$ and $\sigma_{\mathrm{D}}$ are the residual stress and residual strain, respectively; and $\mathrm{E}_{\mathrm{A}}$ is the elastic modulus of unloading at the peak.

The energy drop coefficient $H$ expresses a proportional relationship between the mechanical energy input into the rock and the releasable elastic energy. It demonstrates that the deformation and failure of the brittle rock are the result of energy dissipation and sudden release. $H$ has a certain correlation with the brittle failure of the rock. The larger the $H$ value, the less obvious the brittle stress drop of the rock, and the stronger the ductility. Therefore, the energy drop coefficient $H$ has important reference value for characterizing the degree of rock brittle failure.

\section{Triaxial Test of Sandstone}

In order to find out the failure mechanism of sandstone from the energy perspective and to obtain the relevant mechanical parameters, triaxial tests were performed on typical sandstone samples collected from the Hulusu Mine in Inner Mongolia, China. The test pieces were standard cylinder with a diameter of $50 \mathrm{~mm}$ and a height of $100 \mathrm{~mm}$.

The tests were conducted on the MTS816 rock test system. The device is shown in Figure 2. This system uses a three-axis servo press, which can record the stress-strain curve and thus obtain the data of test piece including residual stress and permanent deformation. The 1-hydraulic system was adopted to load hydraulic oil into 6-triaxial cavity to simulate and control the confining pressure stress state of the test piece. The 3-control system was used to control and operate 9-loading device and to load the test piece [28]. The test adopted the force-displacement mixed control loading system. In the initial stage, different confining pressures were applied to the test piece through force control. Confining pressures were applied to predetermined 


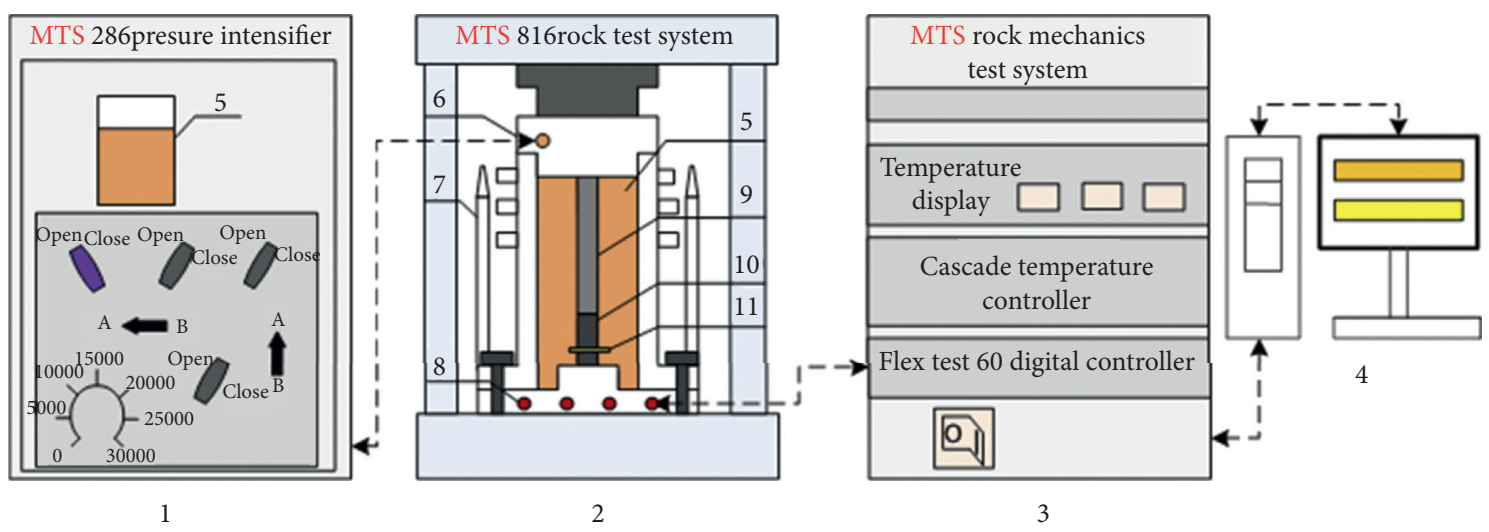

Figure 2: MTS816 test system. (1) Hydraulic control system. (2) Triaxial experimental platform. (3) Control cabinet. (4) Data acquisition system. (5) Hydraulic oil. (6) Confining pressure cavity. (7) Positioning rod. (8) Sensor interface. (9) Loading device. (10) Specimen. (11) Ring extensometer.

values according to different hydrostatic pressures, which were $4,6,8$, and $10 \mathrm{MPa}$. Each confining pressure was applied to five distinct rock test pieces repeatedly. When the confining pressures reached the preset value, the displacement control was used instead, and the axial loading was performed at a loading speed of $0.01 \mathrm{~mm} / \mathrm{s}$ until the test piece failed.

Figure 3 shows the triaxial compressive stress-strain curves of sandstone samples under confining pressures of 4 , 6,8 , and $10 \mathrm{MPa}$, respectively.

It can be learned that before the stress reached its peak value, it increased linearly with the rise of the strain, showing relatively good elasticity. When it reached its peak value, the sample went through buckling failure rapidly, exhibiting obvious brittle stress drop phenomenon. After that, an obvious yielding plateau appeared, which indicated that the sandstones still maintained some ductility under the confining pressures. The carrying capacity increased with the rise of confining pressure. As the confining pressure increased from $4 \mathrm{MPa}$ to $8 \mathrm{MPa}$, the magnitude of stress drop also gradually went up. However, as the confining pressure continued to do so, the magnitude dropped instead. It showed that as the confining pressure increased, the sandstone exhibited the mechanical characteristics of changing from brittleness to ductility and then back to brittleness. This is inconsistent with the characteristic that the brittleness of granite and marble gradually declines with increasing confining pressure. It is difficult to reveal its failure mechanism using traditional energy drop coefficient.

Figure 4 shows the characteristics of the failure surfaces of sandstone samples under different confining pressures. It can be concluded that the samples under different confining pressures had only one shear failure surface which changed along with different confining pressures. Under $4 \mathrm{MPa}$, the macroscopic fracture surfaces of the samples were cracked from the middle, indicating that they had already been completely destroyed under the low confining pressure state, exhibiting distinguished brittleness. As the confining pressure increased, the angles $\theta 1-\theta 3$ between the normal direction of the sandstone failure surface and the horizontal line gradually increased, and the macroscopic failure

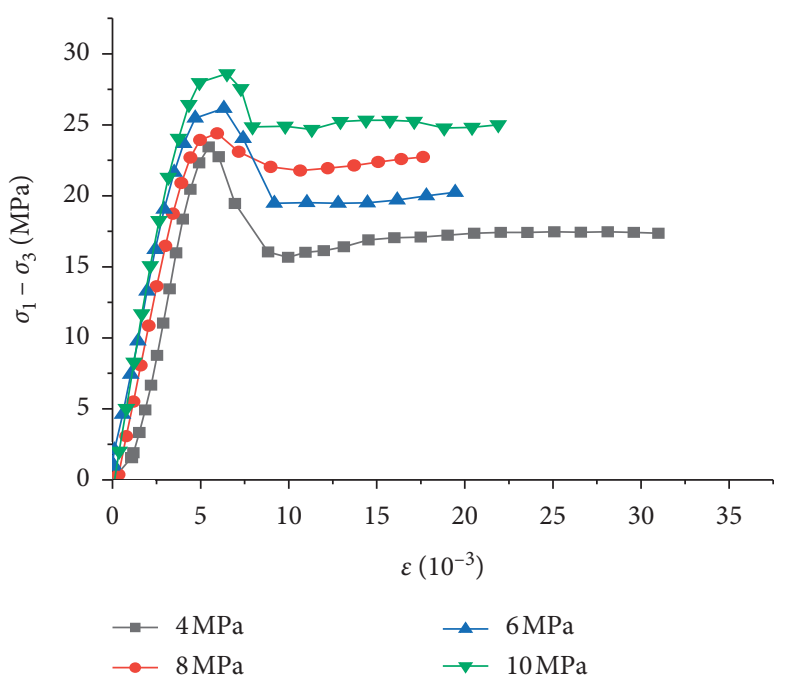

FIGURE 3: Stress-strain curves of sandstone samples under different confining pressures.

surfaces became more and more flat, indicating enhanced ductility of the samples. At $10 \mathrm{MPa}$, the fracture surfaces corresponding to the confining pressures were obviously different from those under other confining pressure states, with $\theta_{3}$ being the largest angle. The surrounding areas were severely fragmented, showing more severe brittleness. This again showed that sandstone has different mechanical properties from marble and granite rocks.

\section{4. "Brittleness-Ductility" Energy Drop Coefficient}

The traditional calculation method of energy drop coefficient has been well applied in rocks such as marble and granite. Based on the results of triaxial tests, it can be concluded that sandstone exhibits transformative characteristics of "brittleness-ductility-brittleness" with increasing confining pressure, which makes it difficult for the energy drop coefficient of brittle rock to fully reflect the deformation and failure process of sandstone. In addition, the traditional 


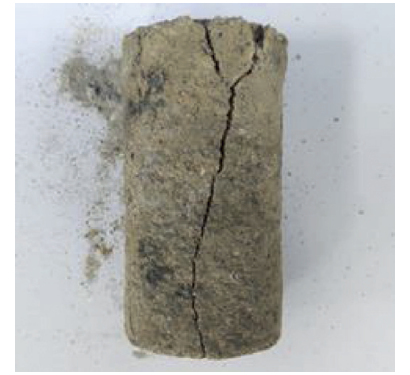

(a)

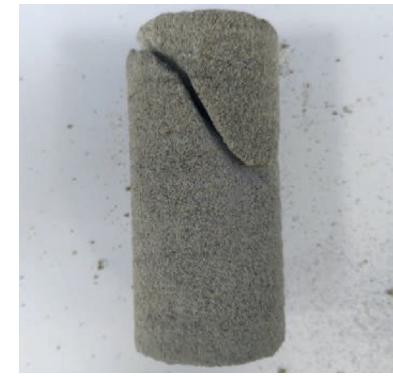

(b)

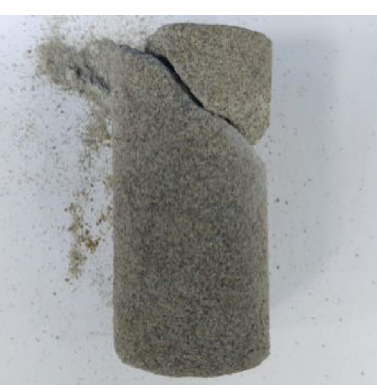

(c)

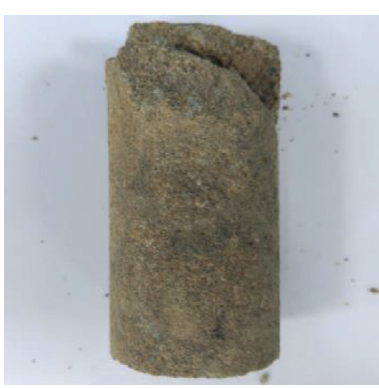

(d)

Figure 4: Failure surfaces of sandstone samples under different confining pressures. (a) $4 \mathrm{MPa}$, (b) $6 \mathrm{MPa}$, (c) $8 \mathrm{MPa}$, (d) $10 \mathrm{MPa}$.

TABLE 1: Calculation of sandstone energy drop coefficients.

\begin{tabular}{|c|c|c|c|c|c|c|c|}
\hline Pressures $(\mathrm{MPa})$ & $S_{\mathrm{BAC}}-S_{\mathrm{EDF}}\left(10^{3} \mathrm{~J} / \mathrm{m}^{3}\right)$ & $2 \mu\left(\varepsilon_{\mathrm{D}}-\varepsilon_{\mathrm{A}}\right) \sigma_{r}\left(10^{3} \mathrm{~J} / \mathrm{m}^{3}\right)$ & $\int_{\varepsilon_{\mathrm{A}}}^{\mathcal{E}_{\mathrm{D}}} \sigma_{z} \mathrm{~d} \varepsilon_{z}\left(10^{3} \mathrm{~J} / \mathrm{m}^{3}\right)$ & $S_{\text {CADF }}\left(10^{3} \mathrm{~J} / \mathrm{m}\right)$ & $H$ & $\mathrm{He}$ & $\theta$ \\
\hline 4 & 29.95 & 6.19 & 100.8 & 60.82 & 0.314 & 1.82 & - \\
\hline 6 & 24.78 & 9.29 & 110.9 & 70.06 & 0.377 & 2.45 & $56^{\circ}$ \\
\hline 8 & 10.07 & 12.38 & 118.8 & 71.30 & 0.381 & 5.85 & $75^{\circ}$ \\
\hline 10 & 15.56 & 15.48 & 165.5 & 82.36 & 0.393 & 4.30 & $82^{\circ}$ \\
\hline
\end{tabular}

method requires the calculation of a large number of integrals. The complicated and cumbersome process is difficult to be applied in practical engineering. Therefore, it is necessary to establish a calculation model that is easy to use and more suitable for sandstone failure characteristics.

When the sandstone enters the ductility stage, the elastic modulus $\mathrm{E}_{\mathrm{A}}$ corresponding to the unloading at the peak in (11) cannot accurately reflect the stress-strain relationship of the samples at this time. When the effect of sandstone damage and defect is not considered, the rock damage factor $\mathrm{D}$ is considered to be 0 . At this time, according to $\mathrm{E}_{\mathrm{D}}=(1-D) \mathrm{E}_{\mathrm{A}}$, it can be replaced by the elastic modulus $\mathrm{E}_{\mathrm{D}}$ corresponding to the residual strength unloading. In Figure $1, \mathrm{AB}$ and $\mathrm{DE}$ stand for $\mathrm{E}_{\mathrm{A}}$ and $\mathrm{E}_{\mathrm{D}}$, respectively. In order to simplify the calculation method, the area of the stressstrain curve is used to represent the energy involved in the deformation and failure process.

$\int_{\varepsilon_{\mathrm{D}}}^{\varepsilon_{\mathrm{D}}} \sigma_{z} \mathrm{~d} \varepsilon_{z}$ is represented by the area of trapezoid ACDF, which represents the external input of the mechanical energy into the samples after the peak point A. The releasable elastic energy of the samples can be expressed by the difference between SBAC (in red in Figure 1) and SEDF (in yellow in Figure 1). This value represents the relative magnitudes of the ductility and brittleness of the samples-the smaller the value, the higher the ductility. $2 \mu\left(\varepsilon_{\mathrm{D}}-\varepsilon_{\mathrm{A}}\right) \sigma_{r}$ is represented by $W_{\mathrm{C}}$. Therefore, the energy drop coefficient calculation model for sandstone can be expressed as

$$
H e=\frac{S_{\mathrm{CADF}}-W_{\mathrm{C}}}{S_{\mathrm{vac}}-S_{\mathrm{EDF}}} .
$$

He can better characterize the relative magnitudes of the ductility and brittleness of the rock, which is called the "brittleness-ductility" energy drop coefficient. The coefficient calculation model is more in line with the energy change of the actual failure process of sandstone and can better reflect the energy conversion of the collapse of sandstone at various depths.

\section{Comparison Analysis}

The residual energy, elastic energy, work done by rock samples to hydraulic oil under different confining pressures, and the drop coefficients $H$ and $H e$ obtained by the two different calculation models according to (11) and (12) are calculated, and the results are shown in Table 1 .

It can be learned that as the confining pressure increases, the mechanical energy input of the samples gradually increases; the energy loss caused by the work performed by the samples to the hydraulic oil rises as well; and the releasable elastic energy gradually decreases. The traditional energy drop coefficient of sandstone $H$ and the "brittle-ductile energy drop coefficient" $\mathrm{He}$ have basically the same variation tendency. As the confining pressure increases, the energy drop coefficient also gradually goes up, the brittleness exhibited by the failure of the samples weakens, and the ductility enhances. This proves the correctness of the "brittle-ductility" energy drop coefficient. However, when the confining pressure rises to $10 \mathrm{MPa}$, the $H$ value of the sandstone continues to increase while $\mathrm{He}$ drops. The results show that when the confining pressure rises to $10 \mathrm{MPa}$, the brittleness enhances. This demonstrates that the calculation of the coefficient $\mathrm{He}$ proposed in this paper can better characterize the relative magnitudes of the ductility and brittleness of the rock and thus reflect the physical failure mechanism of sandstone failure more precisely.

\section{Conclusions and Recommendations}

6.1. Conclusions. This paper establishes a calculation model of the "brittle-ductility" energy drop coefficient that characterizes the whole process of sandstone deformation and 
failure from the perspective of energy based on the stressstrain curves of sandstone samples obtained from triaxial tests. It also discusses the influence of confining pressure on energy drop during sandstone failure. The following conclusions are reached:

(1) According to the fracture surface characteristics and stress-strain curves of the sandstone obtained from the triaxial tests, as the confining pressure increases, the brittleness of the failed samples diminishes and then gradually enhances after reaching the peak. This is different from other rocks such as granite and marble.

(2) Compared with traditional energy drop coefficients, the calculation model of "brittleness-ductility" energy drop coefficient proposed in this paper can accurately describe the whole process of sandstone deformation and failure from an energy perspective. At the same time, the improved model is easy to adopt because it can avoid tedious integration calculations.

This model extends the applicable rock types of the energy drop coefficient and enriches the knowledge system of elastoplastic mechanics. At the same time, a deep understanding of the sandstone failure mechanism can ensure the safety of construction and exploitation in mining zones while reducing the environmental damage. It is of great significance for environmental restoration and geological disaster prevention.

6.2. Recommendations. For future research, the following research directions deserve scholarly attention:

This paper only establishes a calculation model for the "brittle-ductility" energy drop coefficient suitable for characterizing the sandstone failure mechanism but does not explain why the tendency of sandstone brittleness to change with confining pressure differs from that of marble and granite. Future research can try to explain the mechanism from the composition and mechanical properties.

According to the genesis, rocks can be divided into magmatic rocks, sedimentary rocks, and metamorphic rocks. In addition to sandstone, there are other common surrounding rocks like mudstone in the mining zones. Difference between different types of rocks is actually very large. The new calculation model proved to be feasible and efficient to describe the failure of sandstone. However, whether it can suit other types of rocks is still unclear. Therefore, more samples could be collected to study the energy drop law. In light of this, the strength thresholds of rocks can be identified by applying correspondent energy coefficients according to rock types to better guide the safe and sustainable production in the mining zones.

\section{Data Availability}

The data are generated from experiments.

\section{Conflicts of Interest}

The authors declare no conflicts of interest.

\section{Acknowledgments}

The authors thank Anhui University for providing laboratory and test system for this study. This research was funded by National Nature Science Foundation of China (51774007), Nature Science Research Project of Anhui Education Department (KJ2018JD03), and AHJZU-Anhui Huali Construction Co. Ltd. Joint Research Project (HYB20190152).

\section{References}

[1] K. Xie, W. Li, and W. Zhao, "Coal chemical industry and its sustainable development in China," Energy, vol. 35, no. 11, pp. 4349-4355, 2010.

[2] M. Cheng and B. Liu, "Analysis on the influence of China's energy consumption on economic growth," Sustainability, vol. 11, no. 14, p. 3982, 2019.

[3] J. L. Hao, B. Q. Cheng, W. S. Lu et al., "Carbon emission reduction in prefabrication construction during materialization stage: a BIM-based life-cycle assessment approach," Science of Total Environment, vol. 723, Article ID 131870, 2020.

[4] Q. Wang, X. Song, and Y. Liu, "China's coal consumption in a globalizing world: insights from multi-regional input-output and structural decomposition analysis," Science of the Total Environment, vol. 711, Article ID 134790, 2019.

[5] B. Q. Cheng, J. W. Li, and W. Y. Vivian, "A case study on large deformation failure mechanism and control techniques for soft rock roadways in tectonic stress areas," Sustainability, vol. 11, no. 13, p. 3510, 2019.

[6] H. Li, B. Zhang, H. Bai et al., "Surface water resource protection in a mining process under varying strata thickness-A case study of buliangou coal mine, China," Sustainability, vol. 10, no. 12, p. 4634, 2018.

[7] S. G. Lei and Z. F. Bian, "Research progress on the environment impacts from underground coal mining in arid western area of China," Acta Ecologica Sinica, vol. 34, no. 11, pp. 2837-2843, 2014.

[8] Q. Liu, X. Li, and M. Hassall, "Evolutionary game analysis and stability control scenarios of coal mine safety inspection system in China based on system dynamics," Safety Science, vol. 80, pp. 13-22, 2015.

[9] J. Liu, H. Liu, X.-L. Yao, and Y. Liu, "Evaluating the sustainability impact of consolidation policy in China's coal mining industry: a data envelopment analysis," Journal of Cleaner Production, vol. 112, pp. 2969-2976, 2016.

[10] M. He, L. R. e Sousa, T. Miranda, and G. Zhu, "Rockburst laboratory tests database - application of data mining techniques," Engineering Geology, vol. 185, pp. 116-130, 2015.

[11] Y. Kang, Q. Liu, G. Gong, and H. Wang, "Application of a combined support system to the weak floor reinforcement in deep underground coal mine," International Journal of Rock Mechanics and Mining Sciences, vol. 71, pp. 143-150, 2014.

[12] H. Xie and D. Rui, "Progress in strength theory of rocks based on fracture mechanics and damage mechanics," Progress in Nature, vol. 14, no. 10, pp. 1086-1092, 2004.

[13] D. A. Beck and B. H. G. Brady, "Evaluation and application of controlling parameters for seismic events in hard-rock 
mines," International Journal of Rock Mechanics and Mining Sciences, vol. 39, no. 5, pp. 633-642, 2002.

[14] Z. You, H. Fu, and J. Shi, "Design-by-analogy: a characteristic tree method for geotechnical engineering," Automation in Construction, vol. 87, pp. 13-21, 2018.

[15] M. Q. You and A. Z. Hua, "Fracture of rock specimen and decrement of bearing capacity in uniaxial compression," Chinese Journal of Rock Mechanics and Engineering, vol. 17, no. 3, pp. 292-296, 1998.

[16] J. J. Zhang and B. J. Fu, "Rock burst and its criteria and control," Chinese Journal of Rock Mechanics and Engineering, vol. 27, no. 10, pp. 2034-2042, 2008.

[17] R. Altindag, "Correlation of specific energy with rock brittleness concepts on rock cutting," Journal of South African Institute of Mining and Metallurgy, vol. 103, no. 3, pp. 163171, 2003.

[18] Y. S. Zhao, Z. C. Feng, and Z. J. Wan, "Least energy principle of dynamical failure of rock mass," Chinese Journal of Rock Mechanics and Engineering, vol. 22, no. 11, pp. 1781-1783, 2003.

[19] S. Q. Yang, W. Y. Xu, and C. D. Su, "Study on the deformation failure and energy properties of marble specimen under triaxial," Engineering Mechanics, vol. 24, no. 1, pp. 136-142, 2007.

[20] C. Su and Z. H. Zhang, "Analysis of plastic deformation and energy property of marble under pseudo-triaxial," Chinese Journal of Rock Mechanics and Engineering, vol. 27, no. 2, pp. 273-280, 2008.

[21] H. P. Xie and Y. Ju, "Energy mechanism of deformation and failure of rock masses," Chinese Journal of Rock Mechanics and Engineering, vol. 27, no. 9, pp. 1729-1740, 2008.

[22] J. Zuo and Y. Huang, "Study of energy-drop coefficient of brittle rock failure," Rock and Soil Mechanics, vol. 35, no. 2, pp. 321-327, 2014.

[23] H. Song and J. P. Zuo, "Revised energy drop coefficient based on energy characteristics in the whole process of rock failure," Rock and Soil Mechanics, vol. 40, no. 1, pp. 1-9, 2019.

[24] J.-B. Liu, J. Zhao, H. He, and Z. Shao, "Valency-based topological descriptors and structural property of the generalized sierpiński networks," Journal of Statistical Physics, vol. 177, no. 6, pp. 1131-1147, 2019.

[25] J. B. Liu, J. Zhao, and Z. Cai, "On the generalized adjacency, Laplacian and sign less Laplacian spectra of the weighted edge corona networks," Physica A, vol. 540, Article ID 123073, 2020.

[26] Z. H. Wang, L. Li, Y. X. Zhang et al., "Reinforcement model considering slip effect," Engineering Structures, vol. 198, Article ID 109493, 2019.

[27] Z. H. Wang, L. Li, and Y. X. Zhang, "Bond-slip model considering freeze-thaw damage effect of concrete and its application," Engineering Structures, vol. 201, Article ID 109831, 2019.

[28] W. Ma, Y. Li, K. W. Ding et al., "Mechanical properties of new dry-type beam-column bolt connection Joint," Sustainability, vol. 11, Article ID 134790, no. 12, 3348 pages, 2019. 